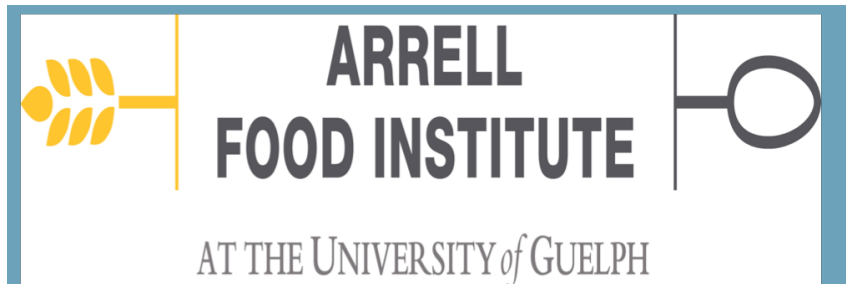

COllege of SOCIAL AND Applied Human SCIENCES DEPARTMENT OF GEOGRAPHY, ENVIRONMENT

AT THE UNIVERSITY of GUELPH AND GEOMATICS

\title{
The Social Disruptiveness of Digital Agricultural Technologies: Asking Questions in the Context(s) that Matter
}

Abdul-Rahim Abdulai PHD Student-Department of Geography, Environment and Geomatics Arrell Food Institute

UNIVERSITY

of GUELPH

IMPROVE LIFE. 


\section{Presentation Outline}

$>$ Technological changes in agriculture

$>$ Digital Agriculture

$>$ Emerging Discourses

$>$ Digging into the social dimensions

$>$ Implications

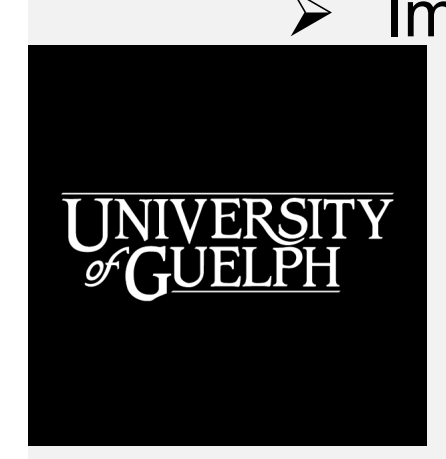

Digital Transformation in Agriculture

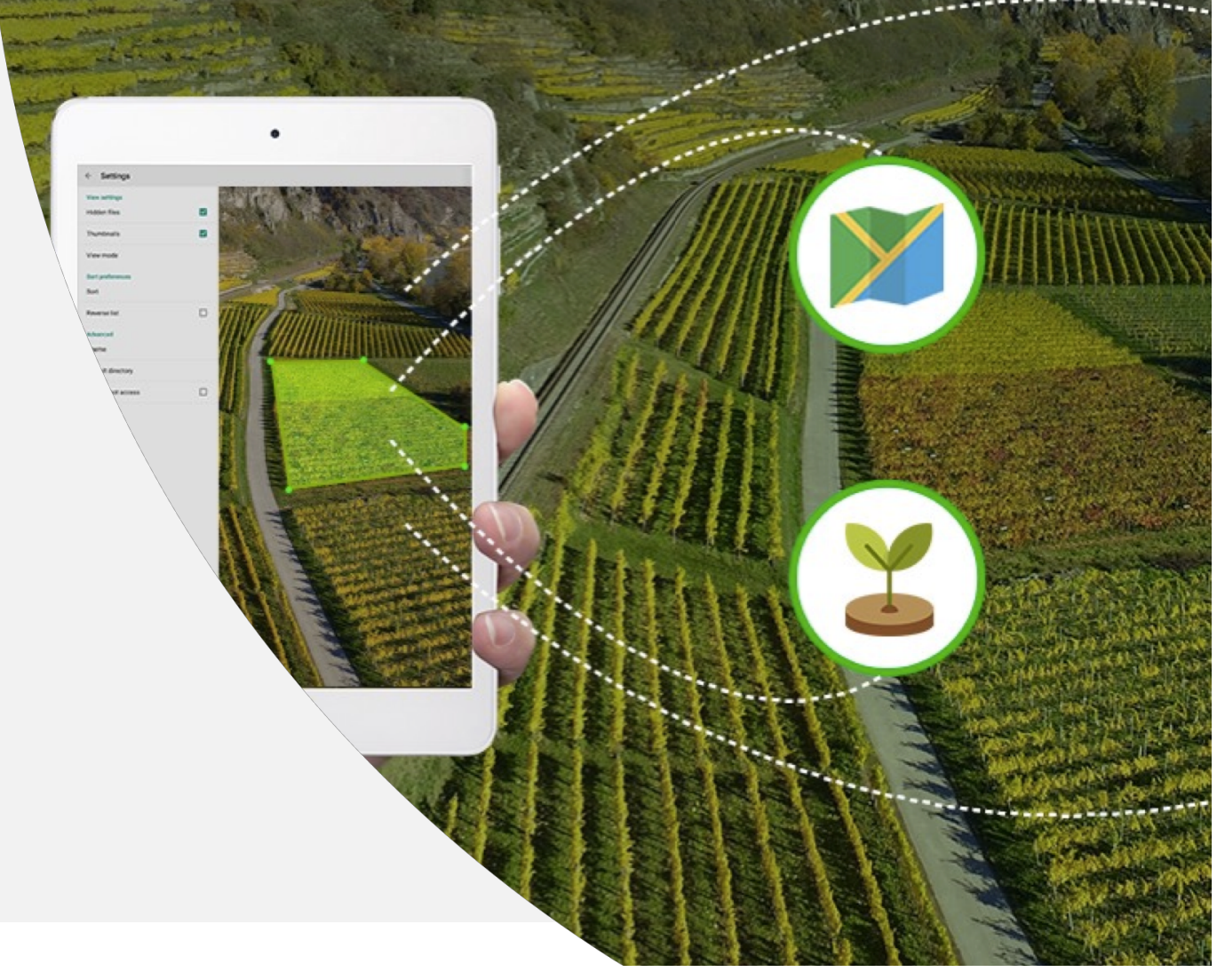




\section{Technological Evolution in Agriculture}

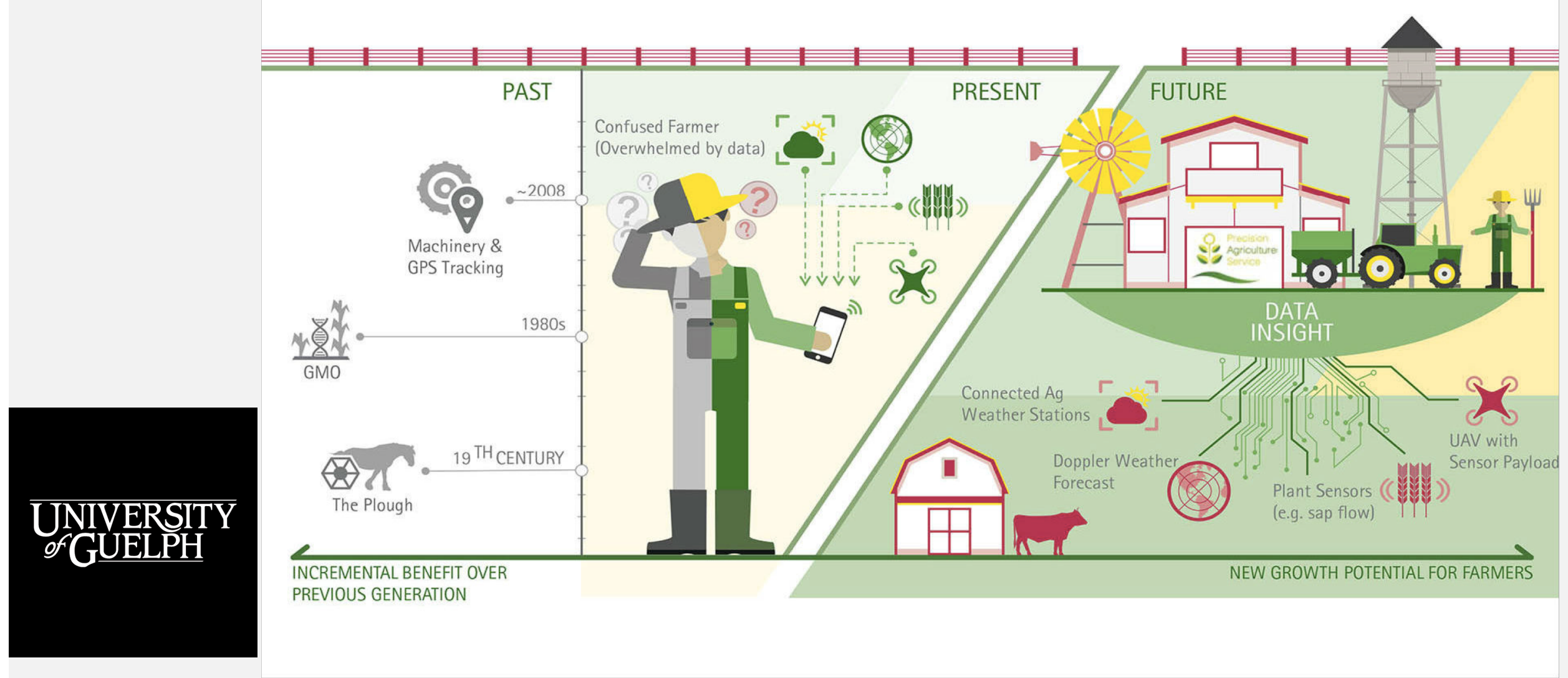




\section{Digitising 'the farm'}

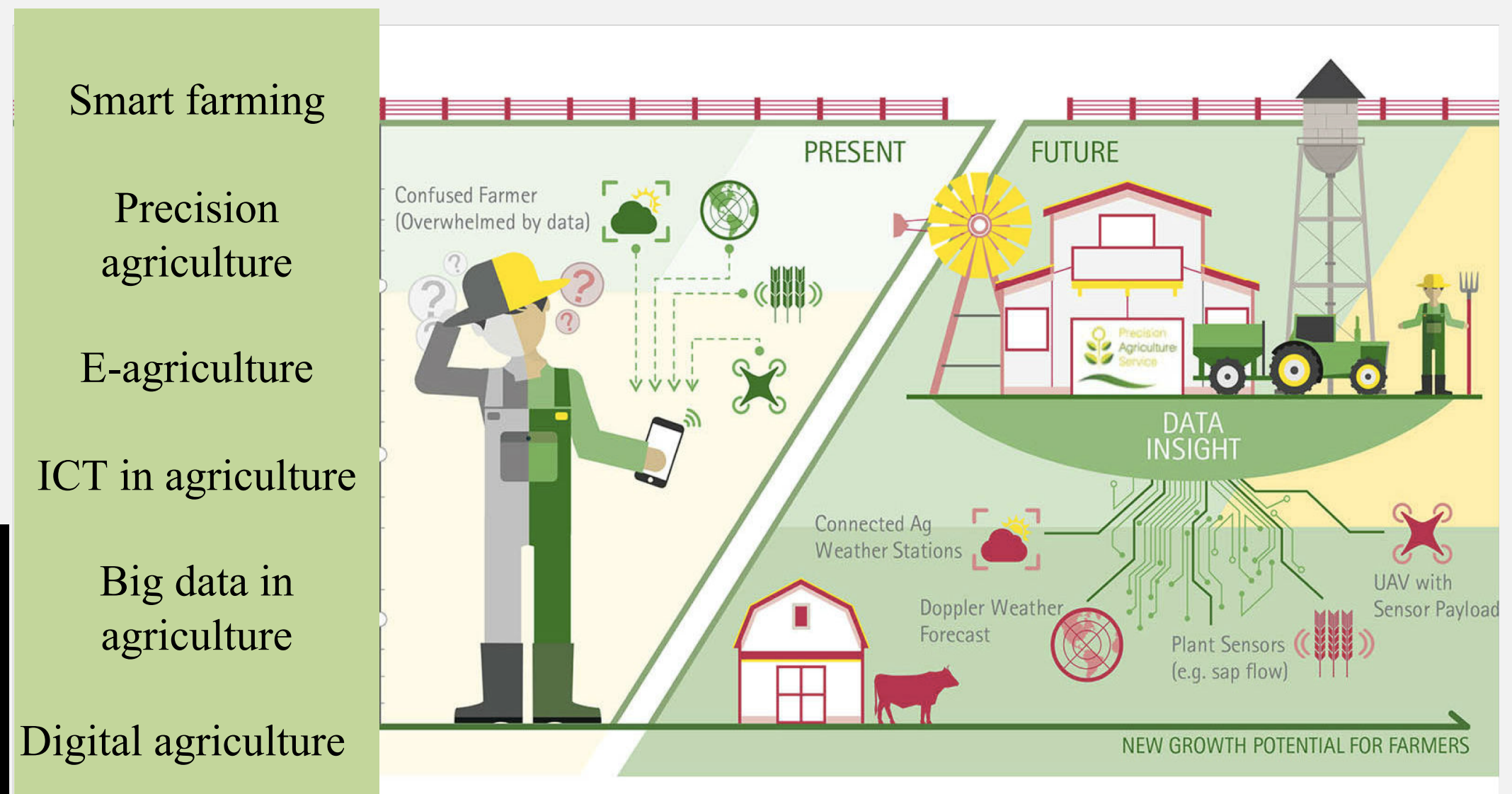

UNIVERSITY of GUELPH 


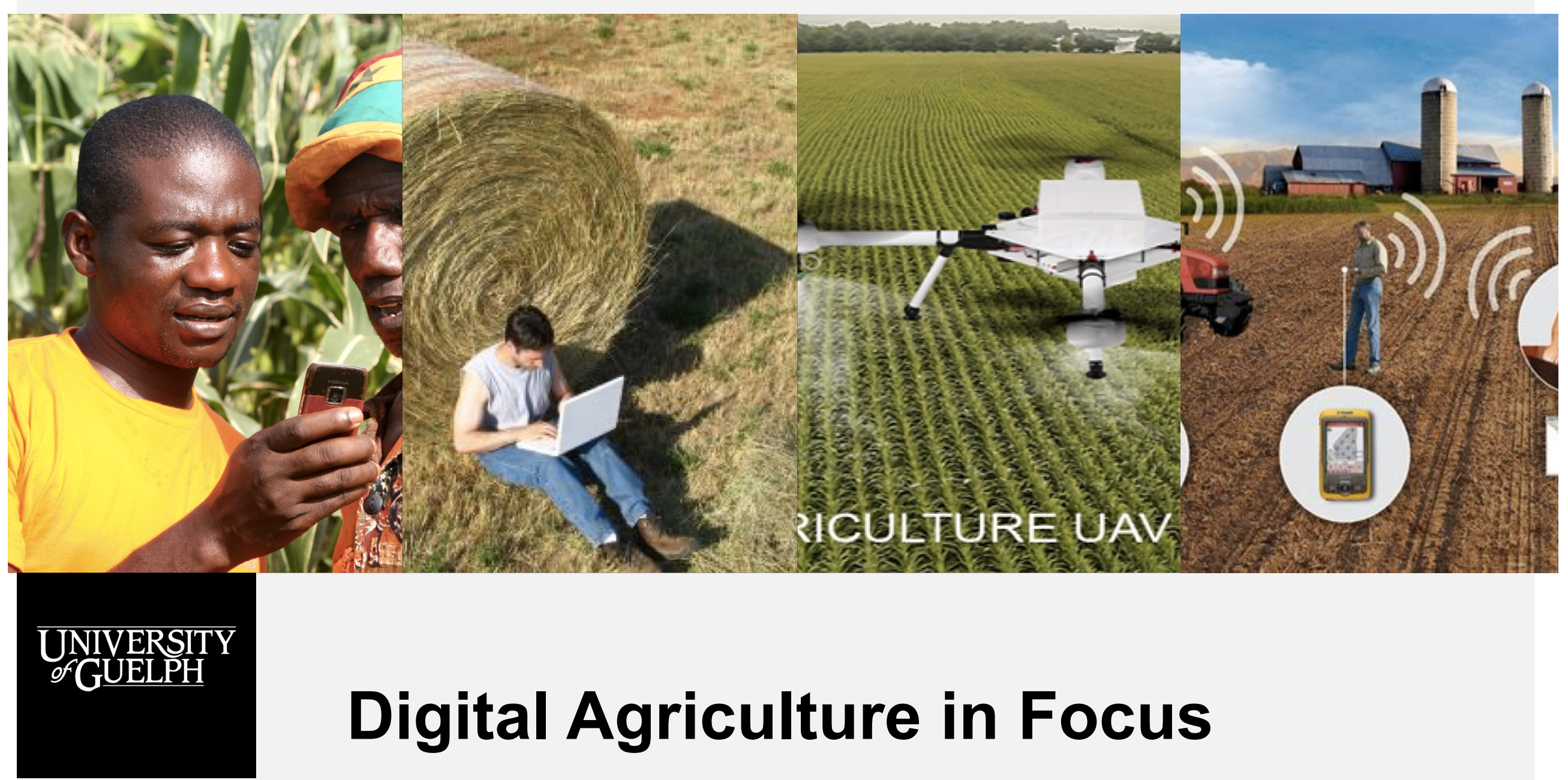




\section{Emerging Issues and Questions}

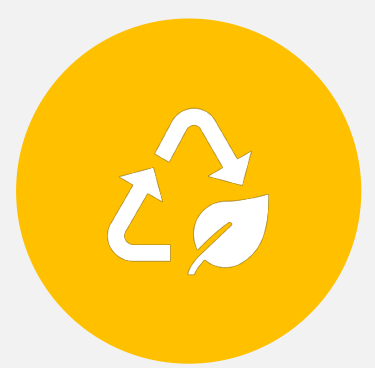

Economic and

Environmental Impacts

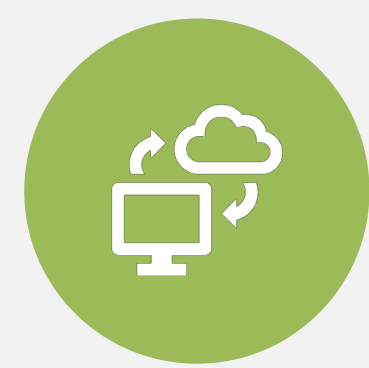

Big Data Issues

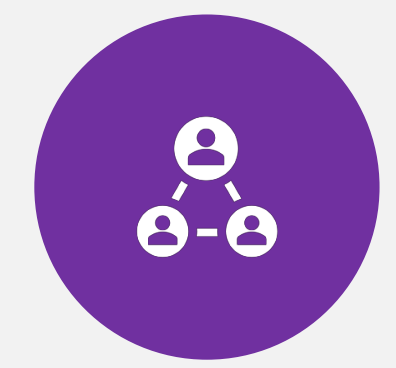

Social Impacts

???

UNIVERSITY

of GUELPH 


\section{Emerging Issues and Questions}
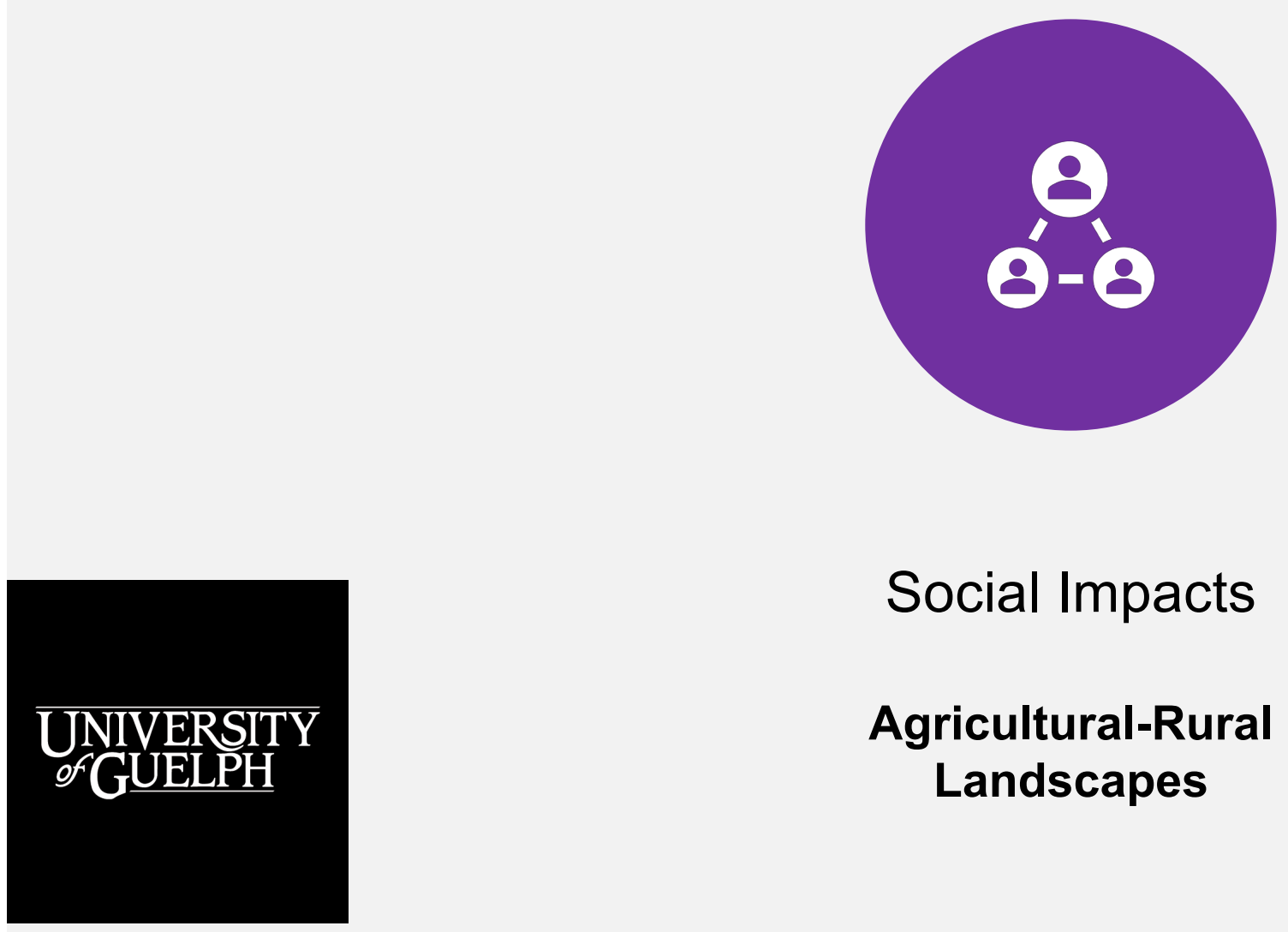

Social Impacts

Agricultural-Rural

Landscapes 


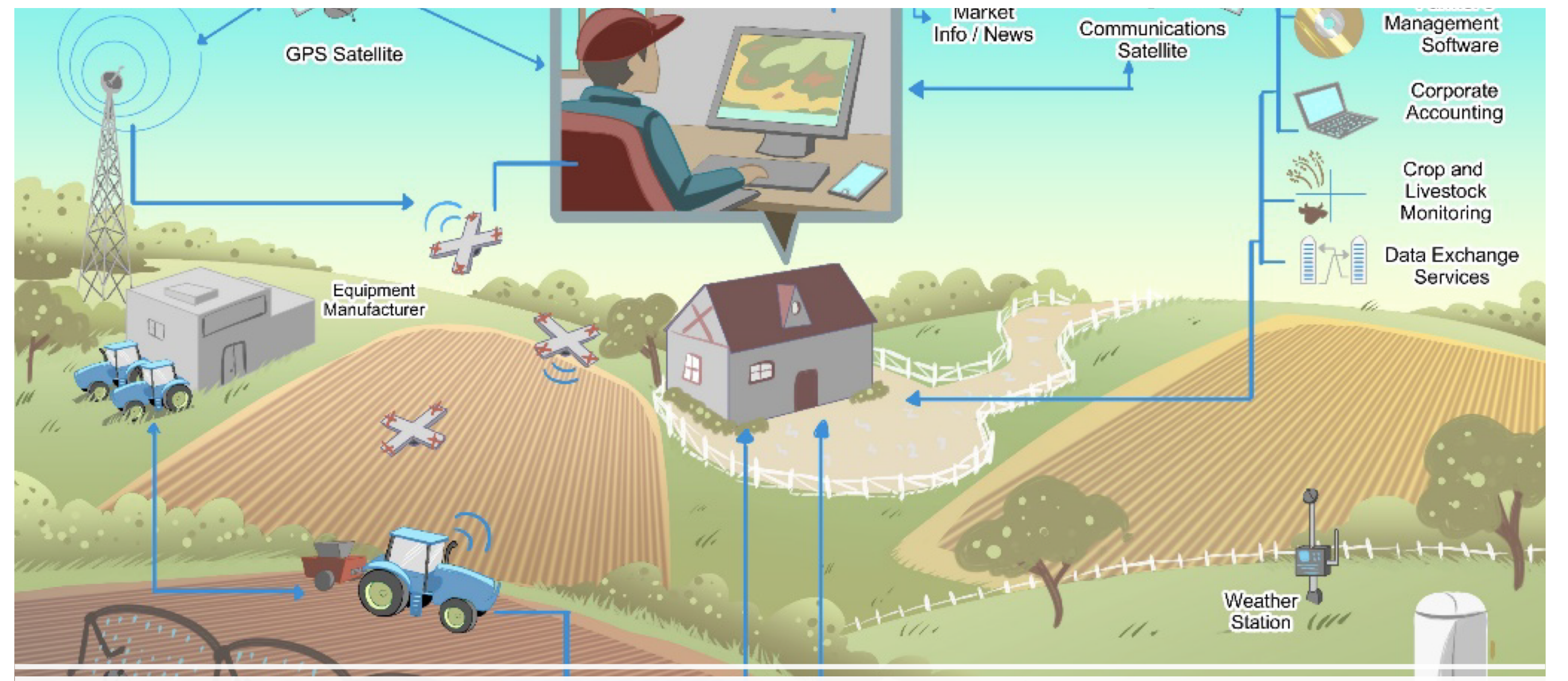

\section{To the countryside???? Rose and Chilvers (2018: 1) “...agricultural societies (rural areas)} may be changed, or "re-scripted"

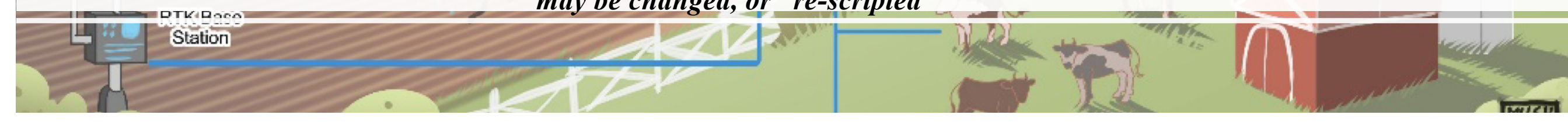




\section{Curious About.....What and How?}

> Social drivers and resistance to digital technologies

"How digital agricultural technologies could "rescript" the rural

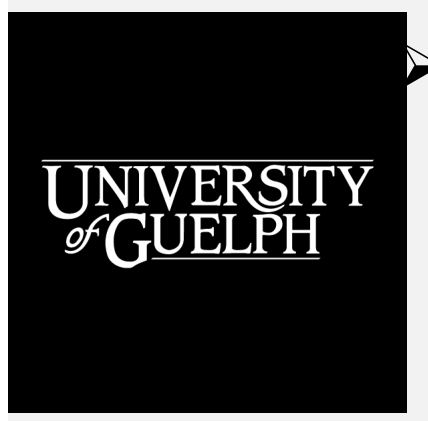

Mechanisms and strategies towards socially sustainable integration in rural areas

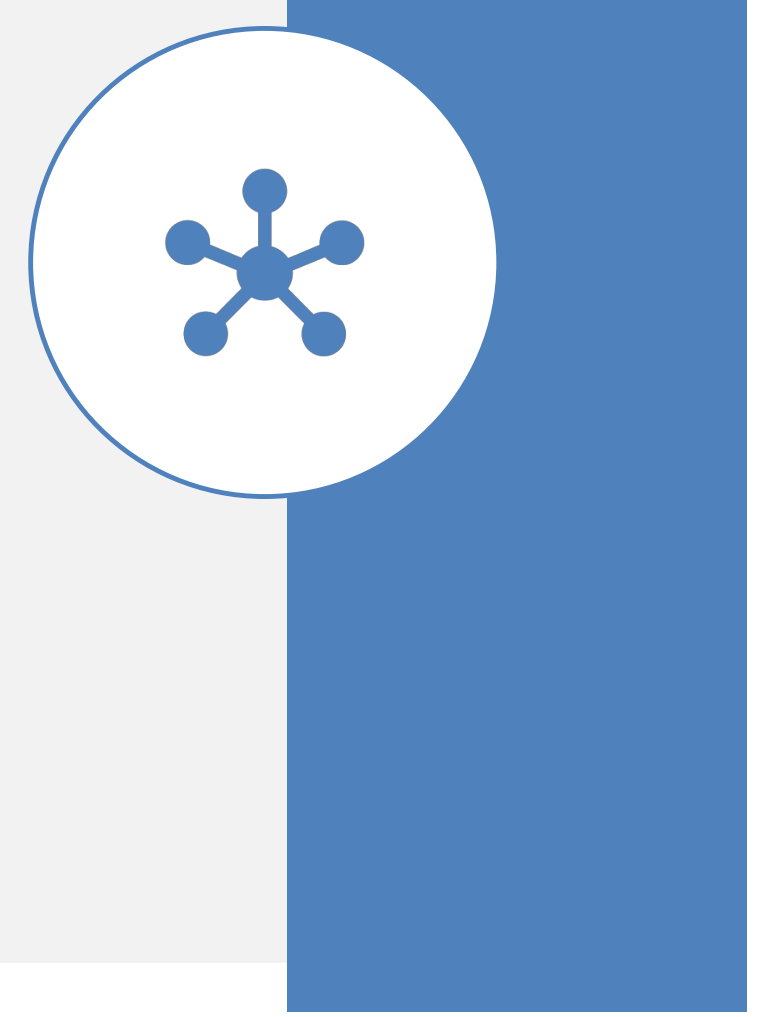



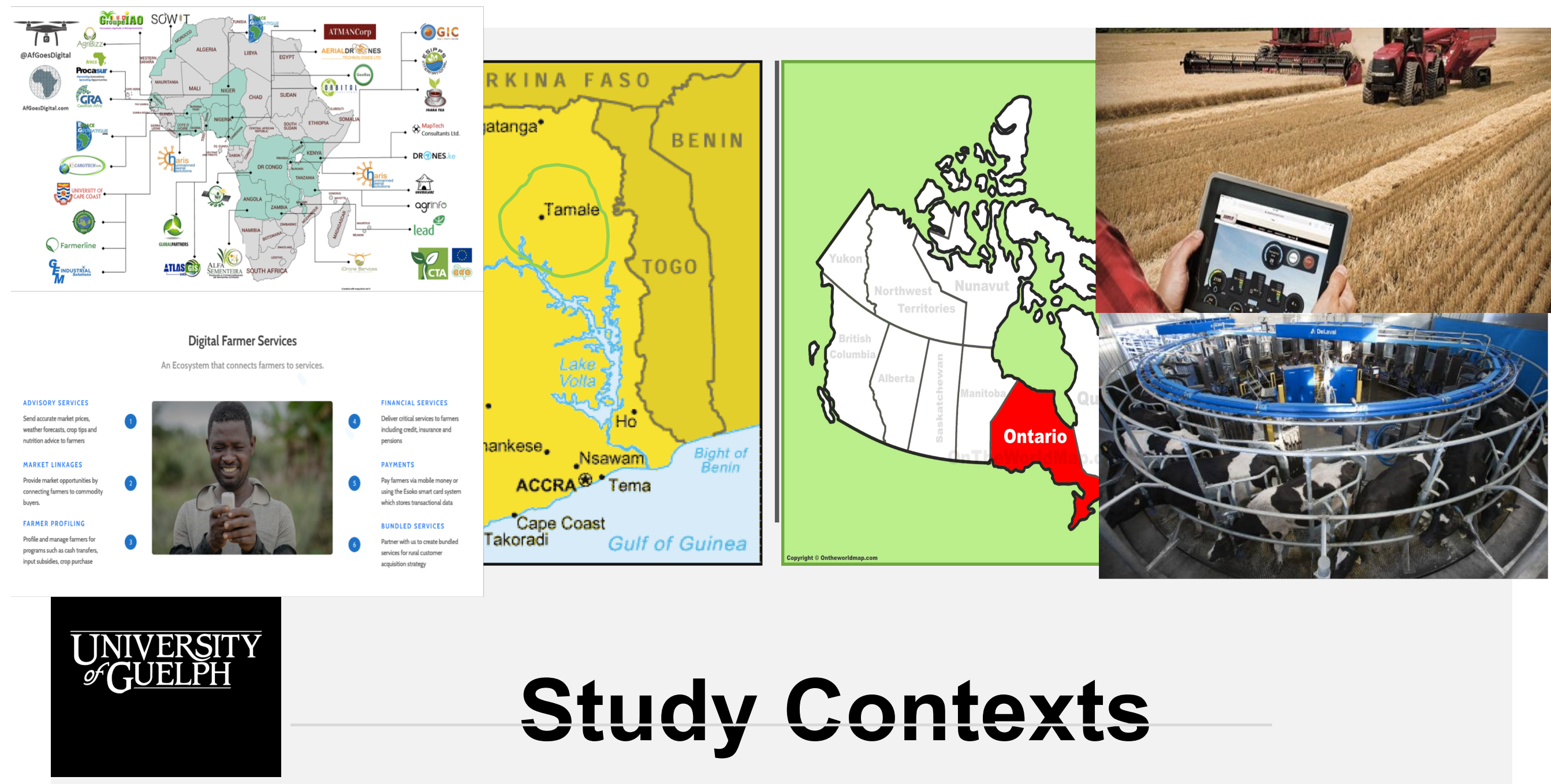

Study Contexts 


\section{Implications for rural}

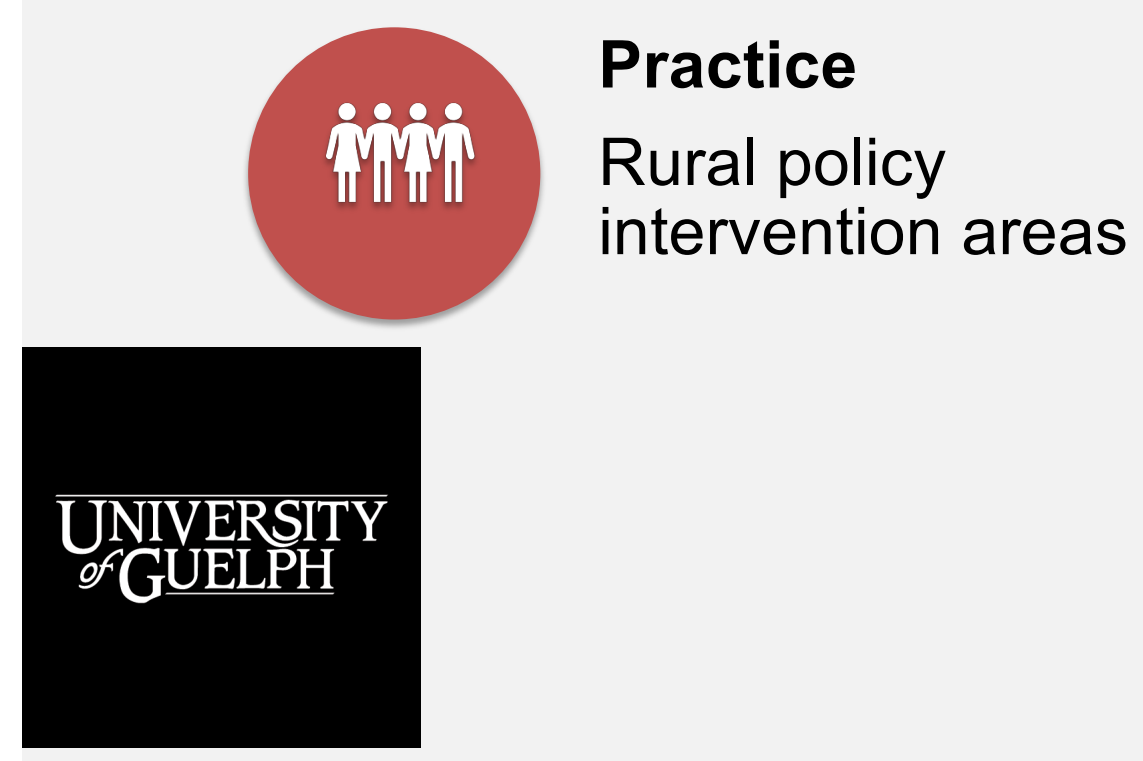

Research

Spaces for further research 


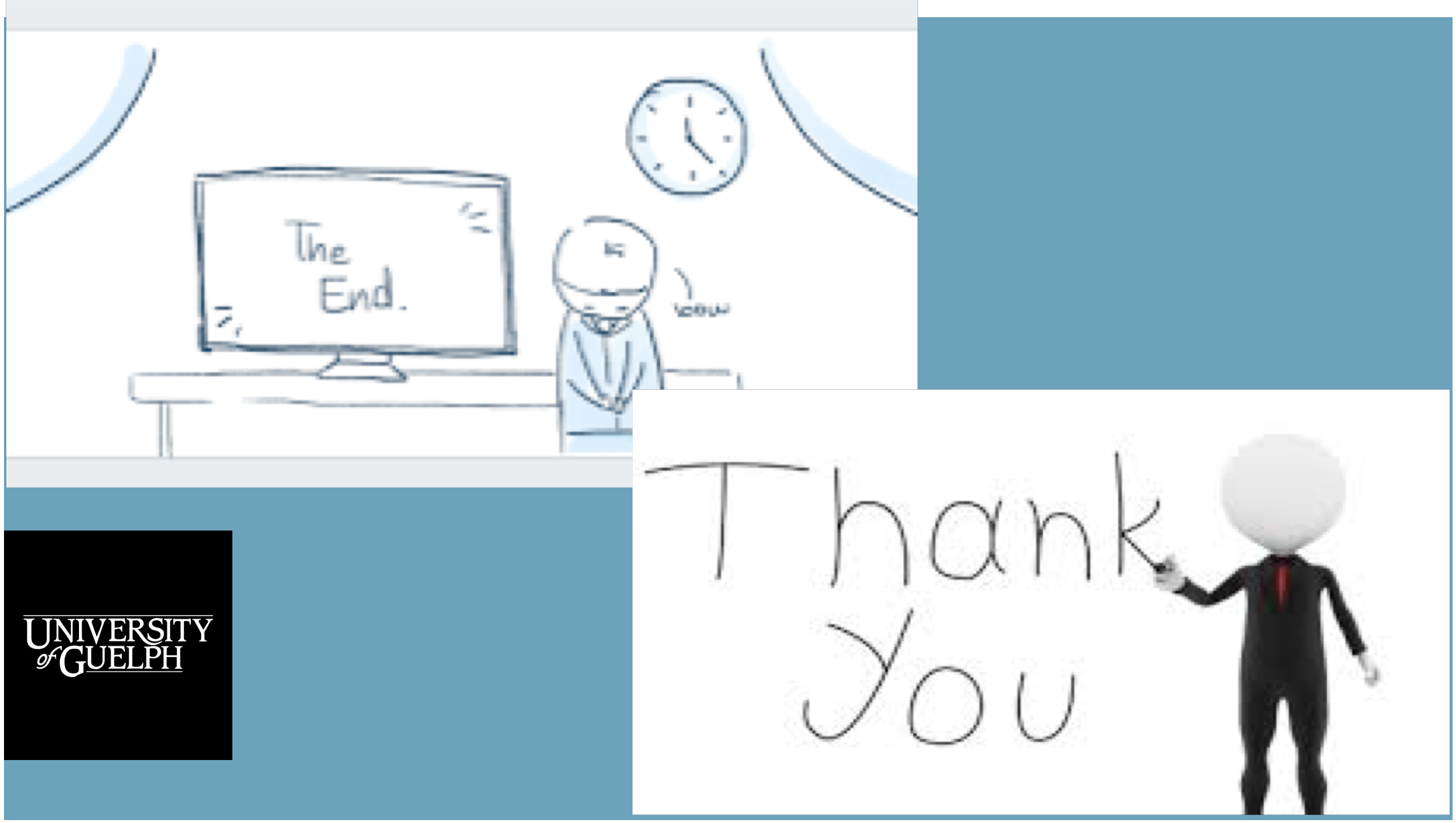



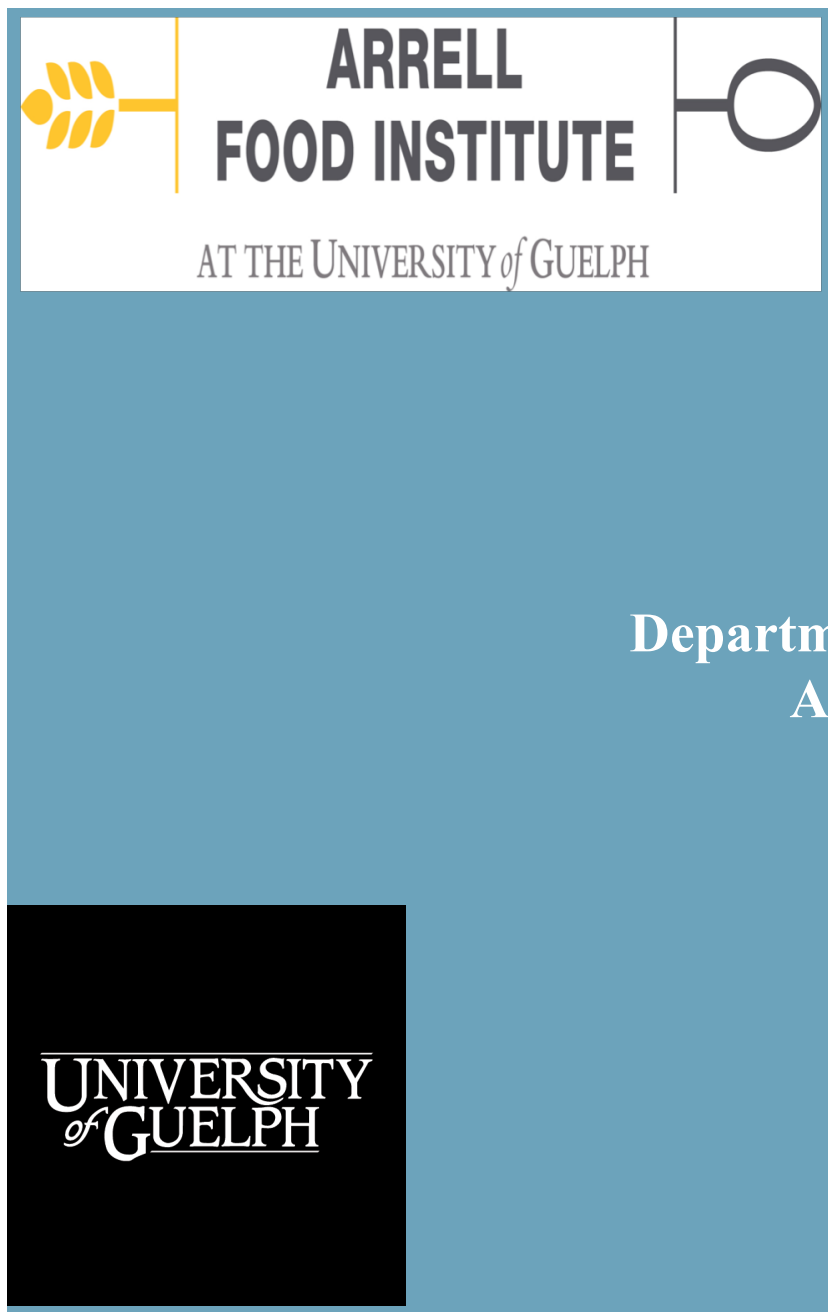

\author{
Abdul-Rahim Abdulai \\ Ph.D. Student, @Feeding 9 Billion \\ Department of Geography, Environment and Geomatics, \\ Arrell Food Institute | University of Guelph \\ Office-----Hutt -R355 \\ email: aabdulai@uoguelph.ca \\ Website: TheHive, Twitter: alollo91
}




\section{The Social??????}

By social impacts I am referring to the consequences on "the ways in which people live, work, play, relate to one another, organize to meet their needs and generally cope as members of society. The term also includes cultural impacts involving changes to the norms, values, and beliefs that guide and rationalize their cognition of themselves and their society"

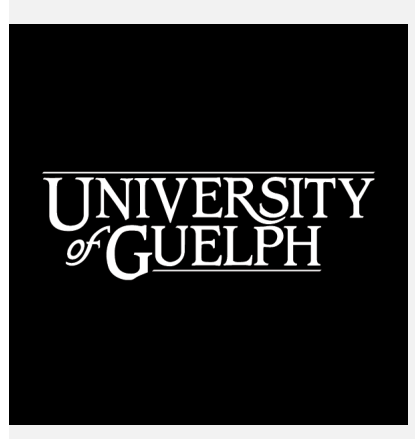

(Interorganizational Committee on Principles and Guidelines for Social Impact Assessment, 2003: 231). 